\title{
Seismic Performance Degeneration of Assembled Concrete Columns with Grouting Defects
}

\author{
Shengcai LI ${ }^{\mathrm{a}, 1}$, Shengxiang SHI ${ }^{\mathrm{a}}$ and Zhongchen $\mathrm{ZHOU}^{\mathrm{a}}$ \\ ${ }^{a}$ College of Architectural Science and Engineering, Yangzhou University, China
}

\begin{abstract}
In order to evaluate the influence of internal defects of semi-grouting sleeve connection on seismic performance of assembled monolithic columns, four specimens of assembled monolithic concrete column with semi grouting sleeve connecting reinforcement bar were fabricated with $10 \%, 20 \%, 30 \%$ internal defects. The test results show that (1) the assembled columns are all damaged by bending, the grouting layer of the assembled column can be pulled apart easily and the cracks develop more closely on the upper part of the sleeve; (2) the larger the internal defects in the sleeve, the less the cracks on the column, and the less sufficient the cracks development; (3) the seismic energy dissipation capacity of the column without defect is better than that of the defective columns.
\end{abstract}

Keywords. Assembled concrete column, grouting sleeve, quasi-static test, seismic performance degeneration

\section{Introduction}

Grouting sleeve connection is one kind of steel bar connection method commonly used in prefabricated concrete structure. It has been studied for 50 years. Ahmad's experiment show that the addition of shear bond can significantly improve the connection, and sufficient anchoring length can ensure the connection capacity of grouting sleeve [1]. Yu Wenmao's test show that the horizontal bearing capacity of prefabricated columns is about $90 \%$ that of the cast-in-place columns [2]. Yang Xu conducted a test and found out that assembled frame and the cast-in-place frame are damaged by the plastic hinge at the end of the beam; the assembled frame is easy to appear wide cracks in the slurry layer during failure [3]. Gao Rundong investigated that the outstanding problems in the practical operation of grouting such as unstandardized grouting materials, insufficient anchorage length, no slurry outlet and slurry reflux [4]. So far, the studies of seismic performance of prefabricated concrete structures with grouting sleeve connection are mainly focused on the specimens without connection defects. However, internal defects always exit in the grouting sleeve connection and cause adverse effects on assembled structures. Therefore, it is necessary to study the influence of internal defects of grouting sleeve connection on the seismic performance of assembled columns.

\footnotetext{
${ }^{1}$ Shengcai Li, College of Architectural Science and Engineering, Yangzhou University, 225127, China; E-mail: lisc@yzu.edu.cn.
} 


\section{Materials and Methods}

\subsection{Preparation of Specimens}

The specimens are designed to simulate a concrete column connected with semigrouting sleeve and internal defects. The ratio of similitude size is 0.2 . The contrast specimen (ZP) is fabricated with semi-grouting sleeve connection without internal defects, the other three specimens (ZP10, ZP20, ZP30) with different degrees of internal defects. Detail and dimension of the specimens are shown in figure 1 . The degree of internal defects of semi-grouting sleeve connection is simulated by the length of anchorage reinforcement bar. According to the grouting coupler for rebars splicing [5], the anchorage length of reinforcement bar should not be less than 8 times of the diameter. The anchorage length of $\mathrm{ZP}$ without internal defect is $8 \mathrm{~d}$. The internal defect degrees of ZP10, ZP20 and ZP30 are $10 \%, 20 \%$ and $30 \%$ respectively. In response to the internal defect degrees, the anchorage length of ZP10, ZP20 and ZP30 were reduced by $10 \%, 20 \%$ and $30 \%$ respectively. The specimen numbers and defect designs are shown in table 1 .

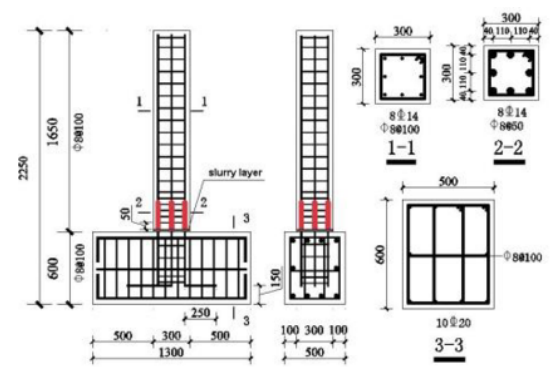

Figure 1. Reinforcements detailing and dimensions ( $\mathrm{mm})$.

Table 1. Internal defects design.

\begin{tabular}{lllll}
\hline Type & $\begin{array}{l}\text { Internal defect } \\
\text { degrees/\% }\end{array}$ & $\begin{array}{l}\text { Anchorage length of } \\
\text { reinforcement bar/mm }\end{array}$ & $\begin{array}{l}\text { Thickness of } \\
\text { slurry layer/mm }\end{array}$ & $\begin{array}{l}\text { Length of } \\
\text { reserved } \\
\text { bar/mm }\end{array}$ \\
\hline ZP & 0 & 112 & 20 & 132 \\
ZP10 & 10 & 101 & 20 & 121 \\
ZP20 & 20 & 90 & 20 & 110 \\
ZP30 & 30 & 79 & 20 & 99 \\
\hline
\end{tabular}

\subsection{Material Properties}

The size and mechanical properties of reinforcement bars in the specimens are listed in table 2 . All the mechanical properties of concrete and grouting material are obtained by normative testing. The concrete grade is $\mathrm{C} 30$. The modulus of concrete is $3 \times 10^{4} \mathrm{MPa}$, the converted axial compressive strength of concrete is $23.5 \mathrm{MPa}$. The grouting material adopted CGM sleeve grouting material and the water/material ratio is $12.5 \%$. The compressive strength and bending strength of grouting material are $89.2 \mathrm{MPa}$ and $13.4 \mathrm{MPa}$ respectively. The sleeve adopts the ductile iron semi-grouting sleeve 
corresponding to the size of the reinforcement bar of the prefabricated column. The relevant technical parameters of the sleeve are shown in table 3.

Table 2. Properties of steel reinforcements.

\begin{tabular}{llll}
\hline Category & $\mathrm{f}_{\mathrm{y}} / \mathrm{MPa}$ & $\mathrm{f}_{\mathrm{u}} / \mathrm{MPa}$ & $\mathrm{E}_{\mathrm{s}} / \mathrm{MPa}$ \\
\hline 14 & 335 & 457 & $2.1 \times 10^{5}$ \\
20 & 434 & 642 & $2 \times 10^{5}$ \\
8 & 463 & 651 & $2 \times 10^{5}$ \\
\hline
\end{tabular}

Table 3. Technical parameters of semi-grouting sleeve

\begin{tabular}{llllll}
\hline Length/mm & $\begin{array}{l}\text { External } \\
\text { diameter/mm }\end{array}$ & $\begin{array}{l}\text { Thread } \\
\text { connection } \\
\text { length/mm }\end{array}$ & $\begin{array}{l}\text { Tensile } \\
\text { strength } / \mathrm{MPa}\end{array}$ & $\begin{array}{l}\text { Extensibility } \\
/ \%\end{array}$ & $\begin{array}{l}\text { Extensibility } \\
/ \%\end{array}$ \\
\hline 162 & 39 & 27 & $\geq 600$ & $\geq 5$ & $\geq 85$ \\
\hline
\end{tabular}

\subsection{Loading Device and Loading Sequence}

The loading equipment are showed in figure 2. The horizontal push-pull force is applied by the MTS electro-hydraulic servo actuator through the loaded beam. The loading direction is specified as push positive and pull negative. The vertical axial pressure is applied by the hydraulic jack applied on the top of the column.

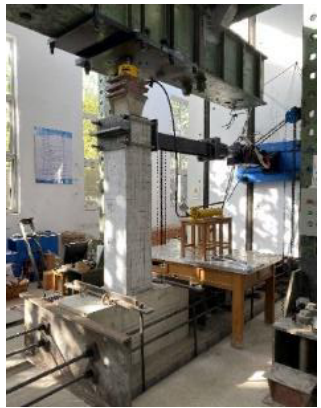

Figure 2. Loading strategy.

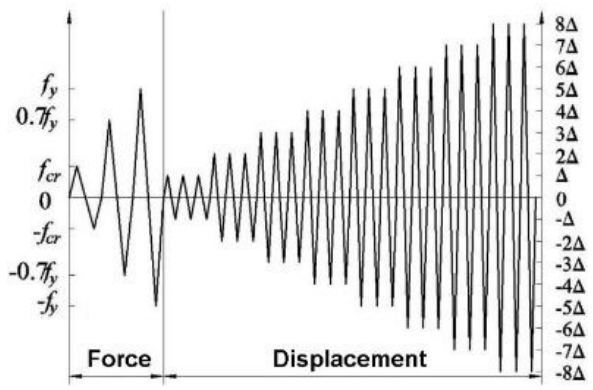

Figure 3. Loading strategy.

According to Specification for seismic test of buildings [6], hybrid loading of force and displacement is adopted to control the horizontal force in the test, the loading strategy shown as figure 3. Before yielding, the test uses force control and each loading step repeats once. After yielding, the test uses displacement control and each loading step repeats thrice and increased by the yielding displacement of ZP.

\section{Test Results and Analysis}

The test results of ZP, ZP10, ZP20 and ZP30 are obtained and compared as following. The yield load $F_{\mathrm{y}}$, yield displacement $\Delta_{\mathrm{y}}$, Peak load $F_{p}$, the displacement corresponding to Peak load $\Delta_{\mathrm{p}}$, ultimate load $F_{\mathrm{u}}$, ultimate displacement $\Delta_{\mathrm{u}}$, are shown in table 4 . The crack distribution and destruction patterns of all tested specimens are shown in figure 4 . 
Table 4. Main test parameters of specimens.

\begin{tabular}{lllllllll}
\hline $\begin{array}{l}\text { SN of } \\
\text { specimen }\end{array}$ & $\begin{array}{l}\text { Loading } \\
\text { direction }\end{array}$ & $F_{\mathrm{y}}(\mathrm{kN})$ & $\Delta_{\mathrm{y}}(\mathrm{mm})$ & $F_{p}(\mathrm{kN})$ & $\bar{F}_{p}(\mathrm{kN})$ & $\begin{array}{l}\Delta_{p} * \\
(\mathrm{~mm})\end{array}$ & $F_{\mathrm{u}}(\mathrm{kN})$ & $\Delta_{\mathrm{u}}(\mathrm{mm})$ \\
\hline ZP & $(+)$ & 60.44 & 14.29 & 77.17 & 77.14 & 26.47 & 65.11 & 69.48 \\
& $(-)$ & 65.67 & 16.39 & 77.11 & & 44.06 & 65.53 & 70.42 \\
ZP10 & $(+)$ & 63.68 & 17.87 & 73.07 & 72.67 & 44.15 & 64.40 & 79.29 \\
& $(-)$ & 63.28 & 21.69 & 72.26 & & 44.05 & 70.08 & 70.42 \\
ZP20 & $(+)$ & 57.34 & 18.44 & 69.03 & 69.36 & 44.12 & 58.87 & 70.43 \\
& $(-)$ & 57.16 & 21.82 & 69.69 & & 44.05 & 65.91 & 61.68 \\
ZP30 & $(+)$ & 50.70 & 22.96 & 64.68 & 64.67 & 44.16 & 57.57 & 79.24 \\
& $(-)$ & 54.58 & 28.31 & 64.66 & & 44.05 & 58.19 & 79.25 \\
\hline
\end{tabular}

$* \Delta_{p}$ represents the displacement corresponding to peak load

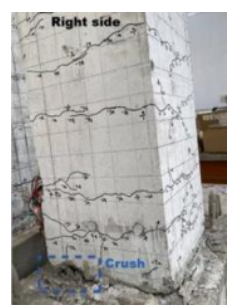

(a) ZP

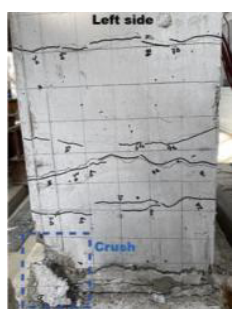

(b) ZP10

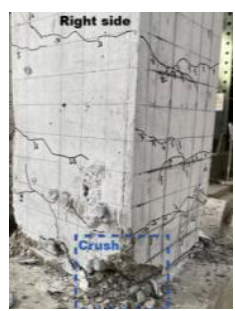

(c) ZP20

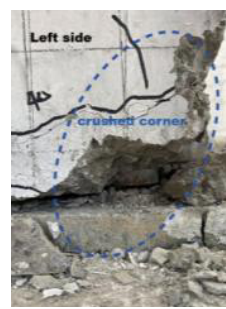

(d) ZP30

Figure 4. Typical damages and crack patterns of the specimens.

The load-displacement hysteretic curves of ZP, ZP10, ZP20 and ZP30 are as shown in figure 5.

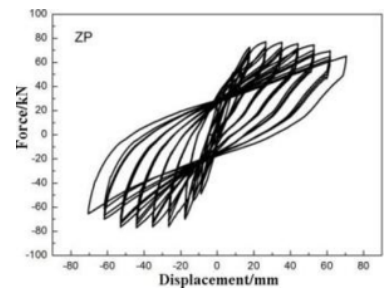

(a) ZP

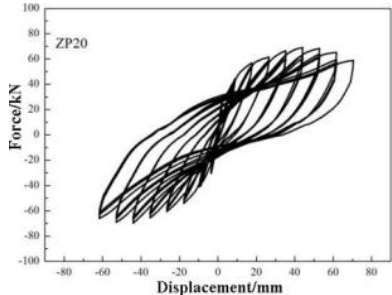

(c) ZP20

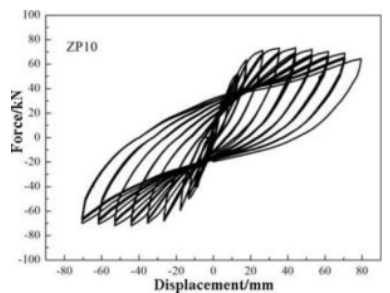

(b) ZP10

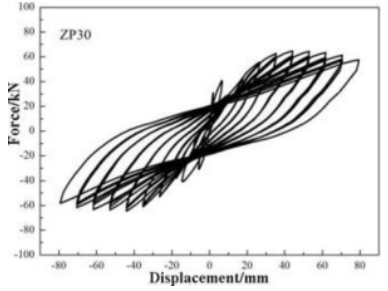

(d) ZP30

Figure 5. Hysteresis loops.

By comparison, ZP has the fullest hysteretic curve and possess excellent seismic energy dissipation capacity. For ZP10, ZP20 and ZP30, with the increase of the internal defects, the hysteretic curves squeezed more obviously and in the same displacement 
loading, the area of the hysteresis loop decreases. The energy dissipation capacity of the specimens decreases when the internal defects of the semi-grouting sleeve connection increases. When ZP30 was loaded to $-40 \mathrm{kN}$, the displacement increased sharply, causing some degree of damage inside the specimen. Especially the rapid development of the cracks on ZP30 at the slurry layer leads to obvious decrease of the stiffness.

\subsection{Skeleton Curves}

The skeleton curves of ZP, ZP10, ZP20 and ZP30 are shown in figure 6. The skeleton curves of the specimens appear differences after the loading displacement exceeding $13.2 \mathrm{~mm}$. The slopes of the skeleton curves and horizontal bearing capacities of ZP10, ZP20 and ZP30 decrease with the increase of internal defects degrees. When positive loading, The peak load of ZP is $77.17 \mathrm{kN}$, and the peak loads of ZP10, ZP20 and ZP30 are $94.8 \%, 89.3 \%$ and $84 \%$ that of $Z P$ respectively. When negative loading, the peak load of ZP is $77.07 \mathrm{kN}$, and the peak loads of ZP10, ZP20 and ZP30 are $93.7 \%, 90.9 \%$ and $84 \%$ that of specimen ZP respectively.

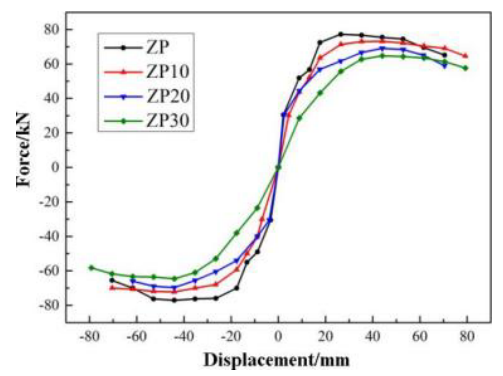

Figure 6. Skeleton curves.

\subsection{Ductility}

The ductility coefficient $\mu$ is calculated according to Eq. (1). Table 5 lists the yield displacement $\Delta_{y}$, the ultimate displacement $\Delta_{u}$ and the ductility coefficient of ZP, ZP10, ZP20 and ZP30 respectively. For ZP, ZP10 and ZP20, the ultimate displacement is the displacement when the horizontal bearing capacity of the specimen drops to $85 \%$ of the peak load. While ZP30 is obviously damaged and not suitable for the continued loading, its ultimate displacement is determined by its last stage loading displacement. The ductility value of specimens as shown at table 5 .

$$
\mu=\Delta u / \Delta y
$$

Table 5. Ductility value of specimens.

\begin{tabular}{lllll}
\hline SN. Of specimen & ZP & ZP10 & ZP20 & ZP30 \\
\hline$\mu$ & 4.58 & 3.84 & 3.32 & 3.12 \\
\hline
\end{tabular}




\subsection{Energy Dissipation}

In order to evaluate the energy dissipation capacity of the specimens, figure 7 indicate the cumulative energy dissipation E, respectively. The equivalent viscous damping coefficient $h_{e}$ is calculated according to Eq. (2).

$$
h_{e}=\frac{S_{(A B C+B E D)}}{2 \pi \times S_{(O A G+O E F)}}
$$

Where $\mathrm{S}_{(\mathrm{ABC}+\mathrm{BED})}$ is the hysteretic loop area of the first cycle at each stage of loading, $\mathrm{S}_{(\mathrm{OAG}+\mathrm{OEF})}$ is the sum of the area of the triangles OAG and the OEF [7].

The cumulative energy dissipation curves of ZP10 and ZP20 are similar with that of $\mathrm{ZP}$, while the cumulative energy consumption curve of ZP30 is obviously lower than others. When the loading displacement reaches $70.4 \mathrm{~mm}$, the cumulative energy consumption of ZP30 is only $72.3 \%$ that of ZP. It can be seen that when the degrees of internal defects are $10 \%$ and $20 \%$, the effects of internal defects on the energy dissipation performance of the specimens are relatively weak, but when the internal defects reach $30 \%$, the energy dissipation capacity of the specimen will be greatly weakened.

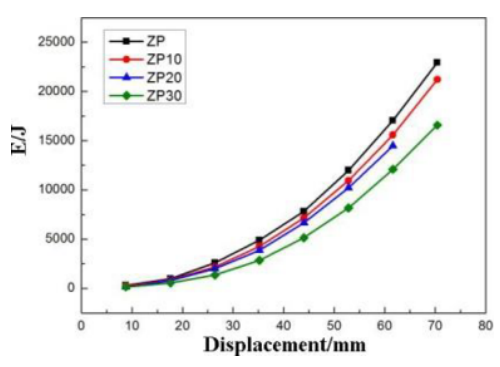

Figure 7. Cumulative energy dissipation.

\section{Conclusion}

Based on the test result, the conclusions can be obtained: (1) The failure modes of the assembled monolithic concrete columns are bending failure. With the increase of internal defects inside the sleeves, the cracks at the combination of prefabricated column and slurry layer will appear earlier. (2) The hysteresis curve of the specimen $\mathrm{ZP}$ without internal defect is the fullest. With the increase of internal defects inside the sleeves, the hysteretic curves of ZP10, ZP20 and ZP30 squeeze more and more obviously, and the energy dissipation capacity of the specimens decreases. (3) The internal defects have great influence on the ductility of the assembled columns connected with the semi-grouting sleeve. The ductility coefficients of ZP10, ZP20 and ZP30 are $84 \%, 72 \%$ and $68 \%$ that of ZP respectively. The seismic deformation ability of the columns has been seriously weakened by the internal defects. 


\section{Acknowledgments}

The work has been supported by the National Natural Science Foundation of China (Grant No. 51478409, 51338001), International cooperation research program of Yangzhou (Grant No. YZ2019148).

\section{Reference}

[1] Rahman ABA, Yee OH. Grout filled steel pipe integrated with shear key for precast concrete connection. Ecosystems and Development. 2016 Aug; 23(7): 49-55.

[2] $\mathrm{Yu}$ WM. Experimental research on seismic behavior of circular concrete columns with grout-filled coupling sleeves. Huaqiao University. 2019 Jun.

[3] Yang X. Experimental research of seismic behavior on monolithic precast concrete frame joints. Beijing University of Civil Engineering and Architecture. 2014 Jun.

[4] Gao RD, Li XM, Xu QF. Existing problems and solutions of sleeve grouting in prefabricated monolithic concrete building. ConstructionTechnology. 2018 May; 47(10):1-4+10.

[5] JG/T398-2012. The grouting sleeve for rebars splicing. Ministry of Housing and Urban-Rural Development of the People's Republic of China, Beijing, 2012 Oct.

[6] JGJ/T101-2015. Specification for seismic test of buildings. Ministry of Housing and Urban-Rural Development of the People's Republic of China, Beijing; 2015 Feb.

[7] Li SC, Zhou ZC, Luo HZ, Milani G, Abruzzese D. Behavior of traditional Chinese mortise - tenon joints: Experimental and numerical insight for coupled vertical and reversed cyclic horizontal loads. Journal of Building Engineering. 2020 Feb; 30: 101257. 